\title{
Developing Drone Experimentation Facility: Progress, Challenges and cUAS Consideration
}

\author{
Dimitri Panagiotakopoulos ${ }^{1}$, Alex Williamson', Ivan Petrunin ${ }^{1}$, Stephen Harman ${ }^{2}$, Tim \\ Quilter $^{2}$, Ian Williams-Wynn ${ }^{3}$, Gavin Goudie ${ }^{3}$, Neil Watson ${ }^{4}$, Phil Vernall ${ }^{4}$, Jonathan \\ Reid $^{5}$, Eimantas Puscius ${ }^{5}$, Adrian Cole ${ }^{1}$, Antonios Tsourdos ${ }^{1}$ \\ ${ }^{1}$ Cranfield University, Cranfield, United Kingdom (UK) \\ email: \{d.panagiotakopoulos; Alex.A.Williamson; i.petrunin; A.C.Cole; a.tsourdos\} @cranfield.ac.uk
}

${ }^{2}$ Aveillant Ltd, Cambridge, UK

email: \{stephen.harman; tim.quilter\}@aveillant.com

${ }^{3}$ Blue Bear Systems Research Ltd, Oakley, Bedford, UK

email: \{Ian.Williams-Wynn; Gavin.Goudie\} @bbsr.co.uk

${ }^{4}$ Thales UK, Crawley, UK

email: \{Philip.Vernall; Neil.Watson\} @uk.thalesgroup.com

${ }^{5}$ Vodafone Group Services Limited, London, UK

email: \{eimantas.puscius1; jonathan.reid\}@vodafone.com

\begin{abstract}
:
The operation of Unmanned Aerial Systems (UAS) is widely recognised to be limited globally by challenges associated with gaining regulatory approval for flight Beyond Visual Line of Sight (BVLOS) from the UAS Remote Pilot. This challenge extends from unmanned aircraft flights having to follow the same 'see and avoid' regulatory principles with respect to collision avoidance as for manned aircraft. Due to the technical challenges of UAS and Remote Pilots being adequately informed of potential traffic threats, this requirement effectively prohibits BVLOS UAS flight in uncontrolled airspace, unless a specific UAS operational airspace is segregated from manned aviation traffic, often achieved by use of a Temporary Danger Area (TDA) or other spatial arrangements.

The UK Civilian Aviation Authority (CAA) has defined a Detect and Avoid (DAA) framework for operators of UAS to follow in order to demonstrate effective collision avoidance capability, and hence the ability to satisfy the 'see and avoid' requirement. The National BVLOS Experimentation Corridor (NBEC) is an initiative to create a drone experimentation facility that incorporates a range of surveillance and navigation information sources, including radars, data fusion, and operational procedures in order to demonstrate a capable DAA System. The NBEC is part located within an active Airodrome Traffic Zone (ATZ) at Cranfield Airport, which further creates the opportunity to develop and test systems and procedures together with an operational Air Traffic Control (ATC) unit. This allows for manned and unmanned traffic to be integrated from both systems and procedural perspectives inside segregated airspace in a first stage, and then subsequently transiting to/from non-segregated airspace. The NBEC provides the environment in which a number of challenges can be addressed.
\end{abstract}

This paper discusses the lack of target performance parameters, the methodology for gaining regulatory approval for non-segregated BVLOS flights and for defining peformance parameters for counter UAS (cUAS). 


\section{Introduction}

A drone experimentation facility is being setup between Cranfield Global Research Airport and Blue Bear Systems Research (BBSR) Twinwoods flight facility to develop and demonstrate new capability whereby Unmanned Aerial Vehicles (UAS) and manned aircraft can jointly operate Beyond Visual Line of Sight (BVLOS) in non-segregated airspace. The facility includes ground infrastructure (radars, communications), procedures and airspace and has been named National BVLOS Experimentation Corridor (NBEC). NBEC aims to provide the environment in which a number of challenges can be addressed that currently prevent the large-scale roll-out of UAS operations into manned aviation airspace. Firstly, the lack of system performance requirements for the enabling communications, navigation and surveillance (CNS) ground infrastructure for BVLOS operations. Unlike manned Air Traffic Services where these are well established [1-2], these safety envelopes need to be quantified and then recommended and endorsed by the National Supervisory Authority (e.g. CAA in the UK). Secondly, gaining regulatory approval for BVLOS flights in non-segregated airspace requires a significant body of evidence which can only be built if such flights are conducted in the first place, this has created a long-standing catch-22 scenario.

NBEC addresses these two challenges by bringing together partners with complimentary expertise, capability, experience and technology, and leveraging its Global Research Airport ecosystem. NBEC has defined a phased approach using flight trials to test and characterise the safety envelopes of the systems to be used in the ecosystem, and at the same time ensure safety assurance mechanisms are followed during the testing phase, to increasingly gather evidence and build confidence for the safe and expeditious integration of UAS BVLOS flights within new and emergent airspace structures. Finally, NBEC investigates a holistic approach to deal with rogue and intruding air vehicles entering the Airport operational environment implementing thus cUAS functionality.

The remainder of the paper is organized as follows. Section 2 provides an overview of the drone experimentation facility, its architecture, sensors and ground infrastructure; Section 3 presents the capability development strategy. It presents the phased approach followed to incrementally gather the appropriate evidence for the ecosystem's individual components and inform the safety, regulatory and performance requirements. Section 4 describes current progress: identification of initial performance parameters and preliminary simulated sensor performance. Finally, Section 5 summarises the salient points of the report and discusses future work.

\section{Drone Experimentation Facility}

\subsection{Experimentation Volume}

The initial NBEC volume consists of a narrow section of airspace extending from Cranfield's Airport Traffic Zone (ATZ) towards BBSR's Twinwoods flight facility 10 miles away and from surface to 400 feet AGL (see Fig. 1). The corridor follows the approach / departure route to the Cranfield main runway; in order to de-conflict with manned aviation traffic, the corridor "dog legs" to the west (approaching the airport). Provision for an aircraft (drone) 'hold' has been made either side of the Cranfield ATZ boundary. The volume has been developed to allow sufficient 'down range' for NBEC's radar and 'hold points' either side of the ATZ boundary to allow airspace management requirements to be taken into account.

The drone experimentation facility is shown in Fig. 2 and consists of a 3D Holographic radar, a Radio Positioning System (RPS), an Unmanned Traffic Management (UTM) system that 
integrates to Air Traffic Control (ATC) and its ADS-B capability. Note that Fig. 2 illustrates only the initial NBEC footprint, i.e. within ATZ, whilst the actual corridor is 10 miles long.

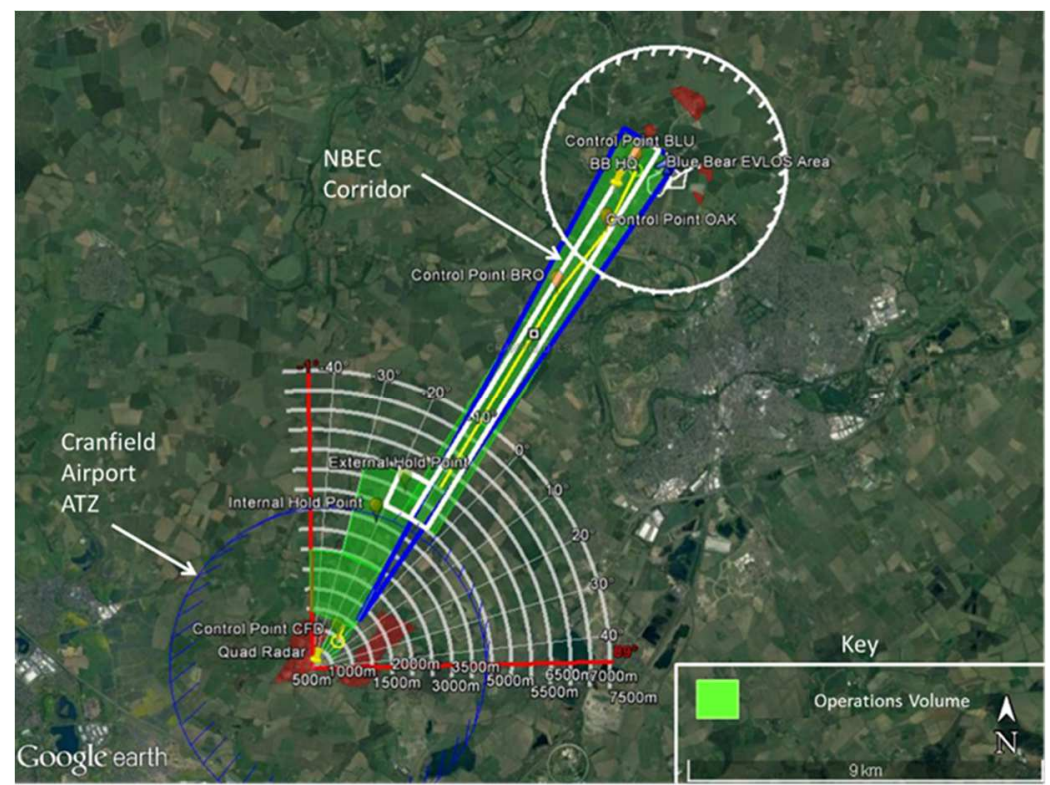

Figure 1. NBEC Test Volume.

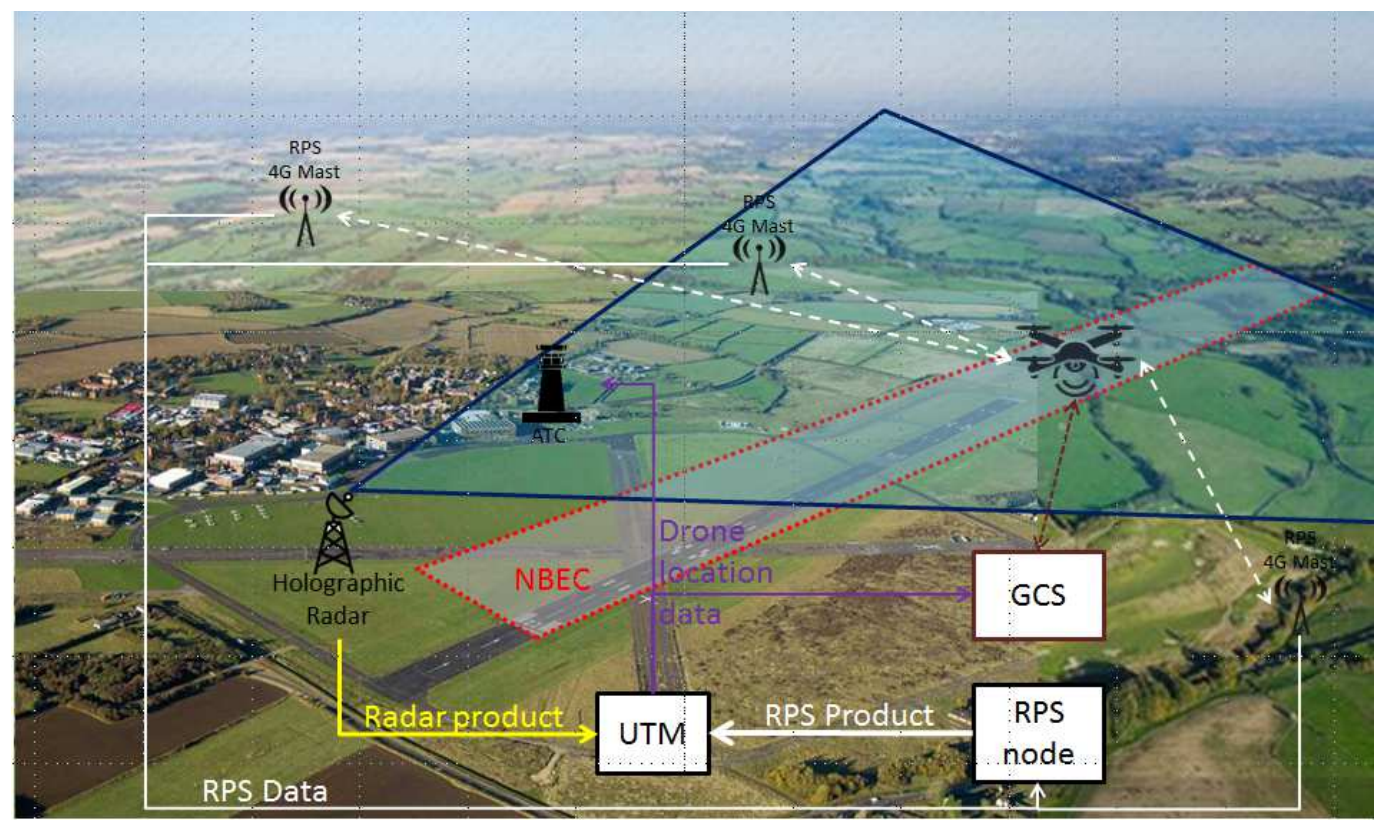

Figure 2. Drone Experimentation Facility Components.

\subsection{Aveillant Holographic Radars}

To provide a non-cooperative target surveillance capability to the overall ecosystem, a 3D holographic radar system is installed. Initially, the Gamekeeper $16 \mathrm{U}$ is employed, which will eventually be replaced by the longer range 'QUAD' demonstrator radar (see Fig. 3). Both are advanced 3D holographic radars developed by Aveillant Ltd and are deployed to provide situational awareness in terms of the localization of all airspace users within the range of the systems. With no moving parts, holographic radars consist of a $2 \mathrm{D}$ receiver array that continuously "floodlights" the entire field of view, resulting into longer coherent integration times and thus providing 3D position and very high Doppler resolution at a high update rate. 
These radar characteristics are crucial for better detection, discrimination and tracking of small, slow, but manoeuvrable targets, such as UAS and other Class G targets, even against stationary clutter and ground targets. The Gamekeeper [3, 4] has been specifically designed for high performance detection of drones and has been deployed at numerous airfields worldwide. Previous work has documented its sensitivity against typical drone targets [5]. Table 1 lists the operating parameters for the Gamekeeper 16U and QUAD sensors.

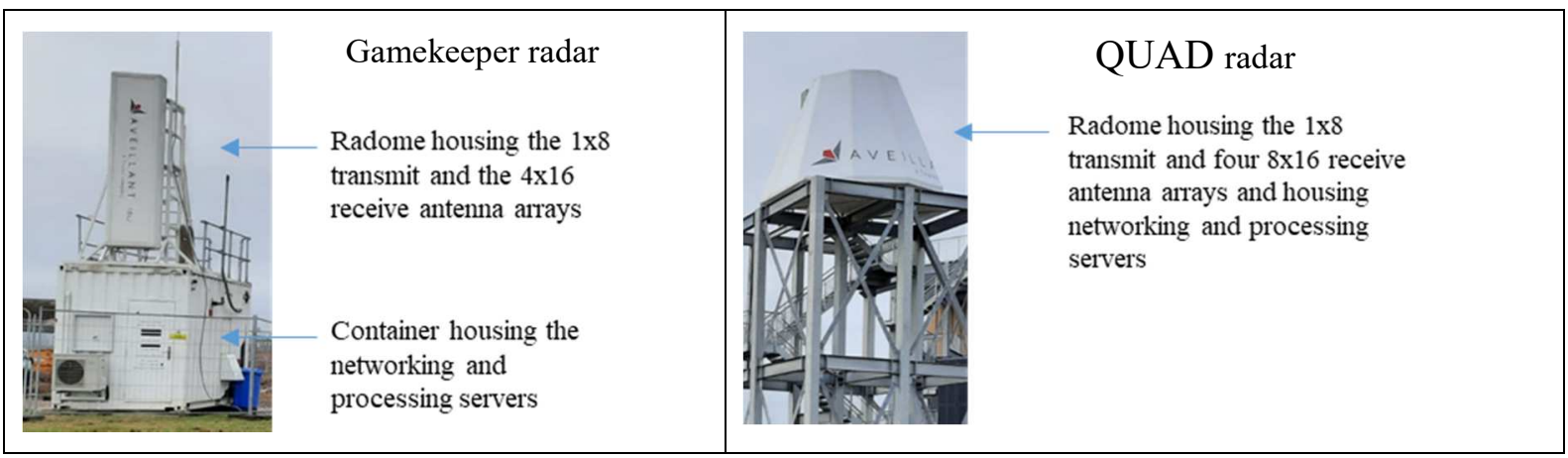

Figure 3. Aveillant Holographic Radars.

Table 1. Gamekeeper 16U and QUAD Radar parameters

\begin{tabular}{l|cc}
\multicolumn{1}{c}{ Parameter } & Gamekeeper Value & QUAD Value \\
\hline Frequency & L band & L band \\
Bandwidth & $\sim 2 \mathrm{MHz}$ & $\sim 2 \mathrm{MHz}$ \\
Transmit power & $>1 \mathrm{~kW}$ & $>12 \mathrm{~kW}$ \\
Receiver channels & $4 \times 16$ & $4 \times 8 \times 16$ \\
Azimuth coverage & $90^{\circ}$ & Up to $90^{\circ}$ \\
Elevation coverage & $30^{\circ}$ & Up to $60^{\circ}$ \\
Update rate & $\sim 0.25 \mathrm{~seconds}$ & Configurable \\
Drone detection range & $7.5 \mathrm{~km}$ & $10 \mathrm{~km}$ (expected)
\end{tabular}

\subsection{Vodafone Radio Positioning System}

RPS provides real-time location of a mobile device by using the ubiquitous Mobile Radio Network information and thus, not relying on having GPS reporting capability (or GPS coverage) on the device. The technology can display information on the quality of the mobile connection plus the reported GPS location, estimated RPS location and the accuracy confidence value simultaneously for drones used for the trial in real time. Moreover, RPS can be used to improve current services (e.g. network optimisation tools and emergency calls accuracy). Table 2 provides a summary of its performance parameters [6,7]. It is used to demonstrate that cellular networks can: (i) be used to identify and distinguish between different UAS; (ii) estimate the location of the UAS independently of GPS telemetry, thus providing a means to verify such telemetry and flag up cases where the GPS location may be being spoofed; and (iii), when required, transmit flight commands to UASs allowing for modifications of flight plans.

Table 2. Vodafone's RPS parameters

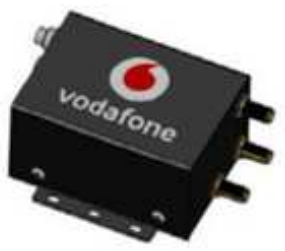

\begin{tabular}{lc} 
Parameter & RPS Value \\
\hline Latency (from mobile network) & $40-50 \mathrm{~ms}$ \\
Update rate & $2 \mathrm{~Hz}(0.5 \mathrm{~s})$ \\
Horizontal accuracy & $+/-150 \mathrm{~m}$ \\
Theoretical limit & $+/-60 \mathrm{~m}$
\end{tabular}

\footnotetext{
${ }^{1}$ In the case of operating a single UAS, the time taken between the mobile network data being sent and a location estimate being produced is around 100 ms which is comparable to GPS,
} 


\subsection{Unmanned Aircraft Systems Traffic Management}

A UTM is installed to provide a composite situational awareness display to the operator (or service provider) by acting as the host for the fusion algorithms and outputs from the various navigation and surveillance technologies. Information is collected and analysed to determine the viability of different solutions and algorithms used to support drone operations in both normal operating and contingency circumstances. The UTM will carry out:-

- Pre-flight flight plan de-confliction and approval, including liaison with local ATC and [Simulated] mission de-confliction with all UAS operations;

- In flight route management, including UAS operation Situational awareness display, Adherence to published plan, Ground-based DAA (GBDAA) function, local ATC liaison and connectivity with UAS operator.

\subsection{Integrated Link to Air Traffic Control}

For the controlled airspace integration, the drone experimentation facility include a link with manned aviation and ATC. Cranfield University has its own Airport, ATC, aircraft (manned and unmanned) and pilots and thus provides a unique sandbox, where concepts, systems and solutions can be tested and validated in a controlled manner in an safe operational environment, obtaining direct feedback from the various stakeholders. To supplement the ATC capability, a new ADS-B workstation was installed for enhanced situational awareness to allow controllers to receive clear identification of any dronesand manned aircraft in the controller airspace which are fitted with a compliant ADS-B transmitter. A dedicated Radar Display Position is currently being procured to further extend the separation and deconfliction capability of the controllers.

\subsection{Data Provision}

For each flight, data is collected from (up to) four independent systems: (i) the holographic radar(s), (ii) the RPS, (iii) the Cranfield Airport's ADS-B system and (iv) the drone's GPS and flight data. Other technologies are being considered for future inclusion (e.g. acoustic sensing). In addition to these data samples, atmospheric conditions will be recorded prior to each trial session, with this information gathered at Cranfield Airport. Table 3 presents the data gathered by each of the four sources and the frequency at which they are logged. These will be used to charctaerise the various safety envelopes for each of the facility components described above.

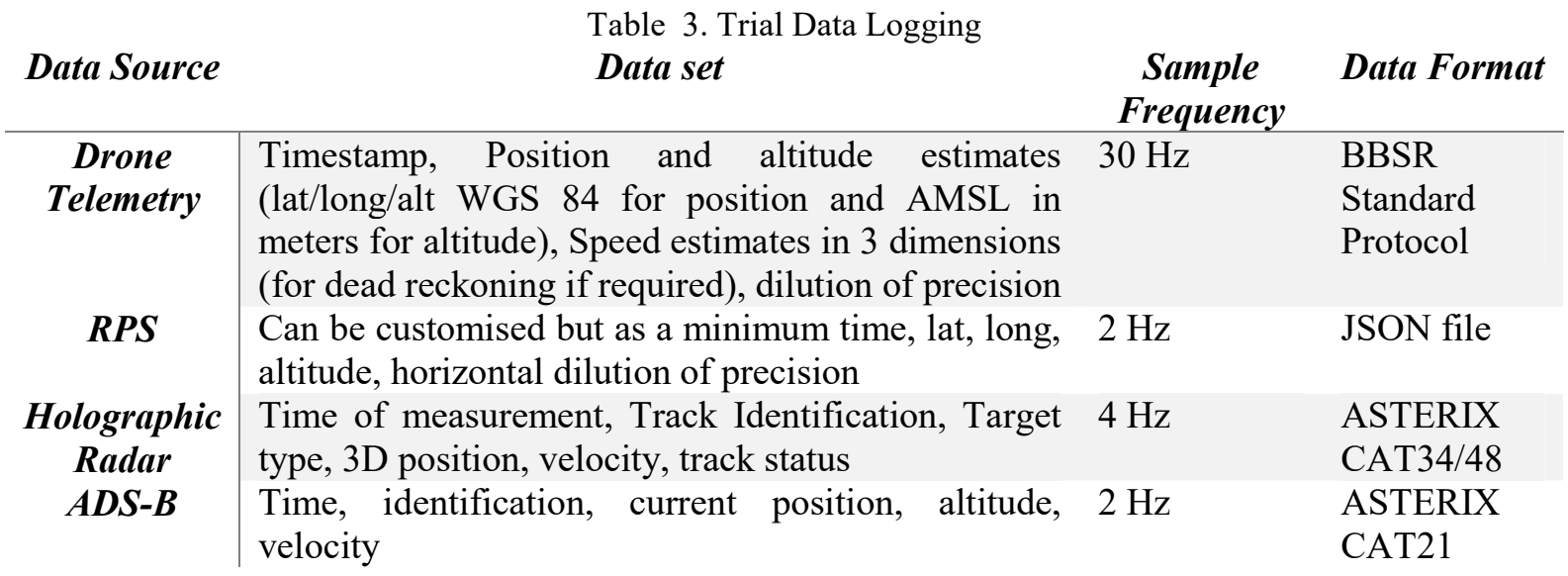




\section{Experimentation Capability Development}

\subsection{Development Strategy}

The test strategy consists of gathering sufficient evidence incrementally to support an operational approval by the CAA's regulatory team to enable routine non-segregated BVLOS flights in uncontrolled (Class $\mathrm{G}$ ) airspace. The test plan focuses primarily on incorporating a DAA ecosystem solution in order to support the flight trial series, addressing the CAA's requirements [8]. To achieve a compliant DAA solution not only is there the technical system automation / autonomy development element, but also the integration with extant manned aviation traffic management systems, processes and procedures. This integration approach will be assessed initially with minimal automation in the UAS management architecture so that the processes and procedures can be fully understood by Air Traffic Controllers including their ability to manage UAS within the ATZ with required response timeliness and accuracy established. The individual test strategy activities are depicted in Fig. 4 and are described below.

To support the trials, the ground infrastructure elements, described in section 2, are deployed in the most suitable position to maximise their coverage and ensure safe flight operations. Each element will go through its own calibration needed for its commissioning, that includes testing through a comprehensive series of visual line of sight (VLOS) / extended visual line of sight (EVLOS) flights (denoted as the single thread flight tests in Fig. 4) designed to support its operational readiness. Those data are captured to formulate their initial performance envelope. Positional information of UAS (and indeed of all airspace users) is required to support the NBEC airspace management, and thus to provide resilience and avoid any single-point-offailure. For this purpose, the ecosystem fuses positional information from the radars and other independent data sources. An assessment of these algorithms will be carried out to assess the accuracy to which they can derive UAS (and/or other airspace users) position not only when all data sources are available, but also as source data degrades and/or ceases.

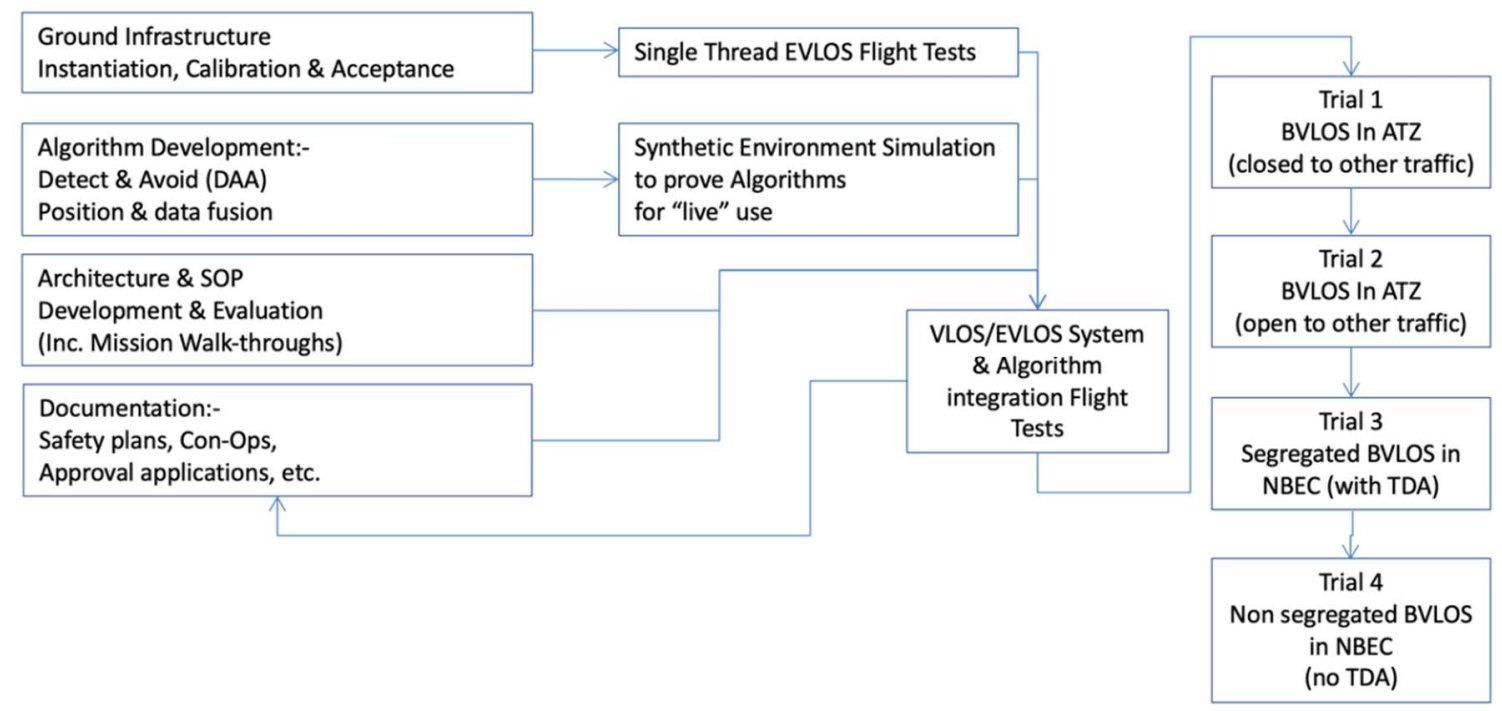

Figure 4. The streamline of the trials / tests

A synthetic environment is developed to carry out assessments of the positioning data fusion and GBDAA prior to being flown in the 'real world' (see Fig. 5). This allows a wide selection of use cases to be modelled, with different operational situations and solution variants, including failure cases, reversionary / contingency planning and adverse meteorological conditions. This ensures robustness testing using numerous simulated "threats" thus allowing 
the system to be stressed without eroding safety margins or increasing risk. Once the entire ecosystem is commissioned and integrated, initial VLOS / EVLOS integration flight tests will be conducted on the same four BVLOS profiles and configuration to prove the flight management processes derived to enable UAS to safely operate within those airspace volumes and to gather DAA performance data. This will finally enable entry into the final BVLOS trials phase, which consists of 4 trials as shown in Fig. 4.

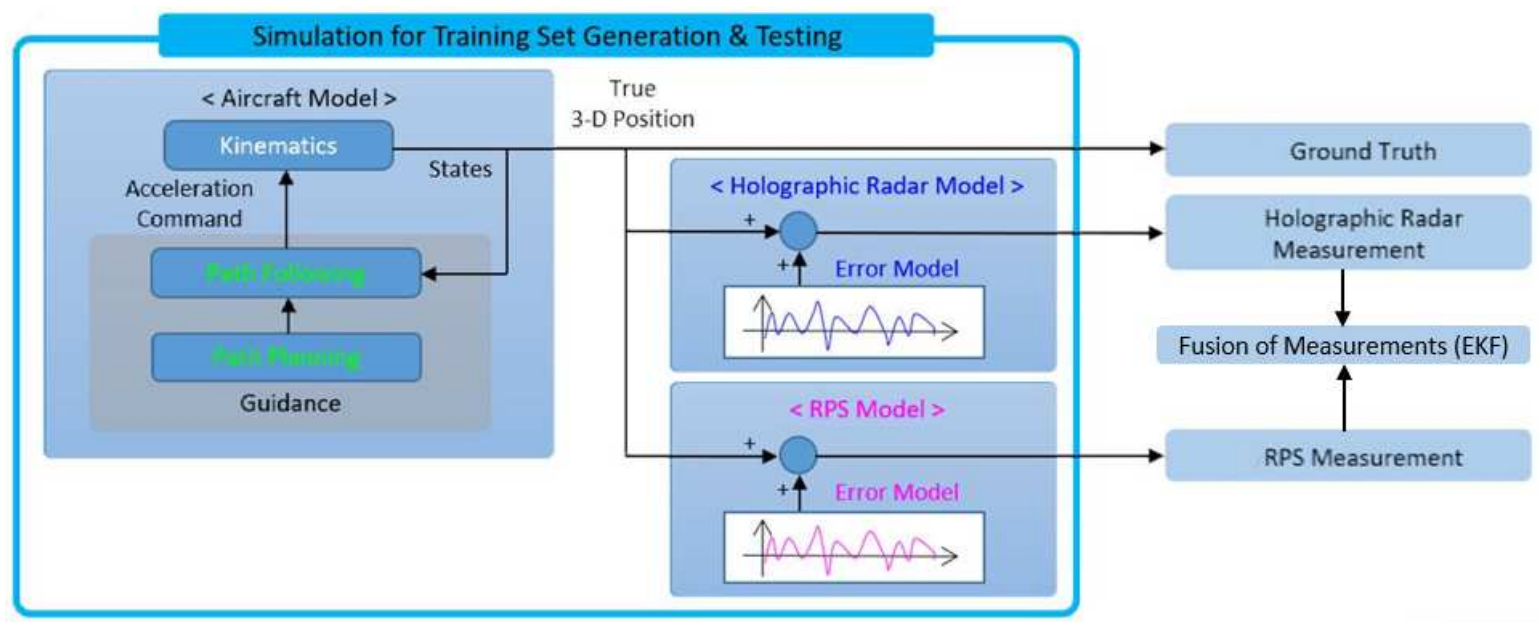

Figure 5. Initial Synthetic Environment for algorithms validation

\subsection{Counter drone capability development}

Existing approaches to deal with rogue and intruding drones at airports have been disparate as drone detection technologies do not yet have institutionalised regulatory requirements. This is because the majority of these systems have been installed for business continuity and security reasons, rather than safety, following major disruptive events at airports such as Gatwick, and Frankfurt [9]. There are currently over 500 counter UAS (cUAS) solutions, which use different techniques [10], none of which is optimal on its own and most airports have a combination of sensors and procedures to mitigate against these threats. The Gamekeeper radar has been installed at major Airports such as London Heathrow, where it forms part of a drone detection and mitigation solution that includes other sensors. This project takes a holistic approach to cUAS by providing a fused output that leverages and combines sensor capability and performance (as per Fig. 5). The trials strategy will gather evidence to produce performance requirements as well as recommended methods (e.g. sensors, procedures, responses, etc.) to detect and mitigate against rogue drone threats. Comparison of all sensors will be conducted in order to ascertain the best method to deal with those threats.

\section{Progress and Challenges}

The first project outputs have been the submission of the BVLOS within the ATZ Operational Safety Case and the CAA's BVLOS DAA Ecosystem exposition, which includes initial target performance (Table 4) and the DAA mitigation strategies (Table 5).

Table 4. Initial Target Performance requirements (from Manned Aviation) 


\begin{tabular}{|c|c|c|}
\hline Requirement for 3 NM separation & Non-cooperative sensor & Cooperative sensor \\
\hline Nominal refresh period & $\leq 5$ seconds & $\leq 5$ seconds \\
\hline $\begin{array}{l}\text { Probability of position update (per } \\
\text { aircraft in global coverage) }\end{array}$ & $\geq 90 \%$ & $\geq 97 \%$ \\
\hline Horizontal position RMS error & $\leq 300 \mathrm{~m}$ in global coverage & $\begin{array}{l}\leq 300 \mathrm{~m} \text { global and } \leq 330 \mathrm{~m} \\
\text { for } 100 \% \text { of the flights }\end{array}$ \\
\hline Average data age & $\leq 2.5$ seconds & $\leq 4$ seconds \\
\hline $\begin{array}{l}\text { Continuity (probability of critical } \\
\text { failure) }\end{array}$ & $\begin{array}{l}\leq 2.5 \quad 10^{-5} \text { per hour of } \\
\text { operation }\end{array}$ & $\leq 2.510^{-5}$ per hour of operation \\
\hline $\begin{array}{l}\text { Probability of update of aircraft } \\
\text { identity with correct value }\end{array}$ & N/A & $\geq 98 \%$ global \\
\hline Delay of change in aircraft identity & N/A & $\leq 15 \mathrm{~s}$ for $100 \%$ of the cases \\
\hline Resolution & \multicolumn{2}{|c|}{$\begin{array}{l}\text { Ability to resolve two aircrafts at } 1 \mathrm{NM} \text {, with a probability of } \\
\text { greater than } 95 \%\end{array}$} \\
\hline
\end{tabular}

There are currently no specific performance requirements set for BVLOS, ground infrastructure or DAA for UAS and UTM, and thus the first baseline NBEC adopted was based on existing manned aviation requirements $[1,2]$, understanding that these would be ratified as evidence is gathered. For reference, Table 4 provides a sample of the requirements for the 3 NM separation provision, which are compared to Tables 1 and 2 that describe the infrastructure (radar and RPS) anticipated performance, based on previous analyses. to provide further insights on potential sensor performance, simulations were carried out using the synthetic environment shown in Fig. 5, as it is expected that these safety envelopes will be tightened as the kinetic characteristics of small drones are lower than commercial aircraft. Initial error figures were obtained as shown in Table 5 for the fused measurement output (through a simple Extended Kalman Filter), which as expected provide over 30\% improvement in performance compared with the individual sensor performance. These simulated results will be validated by the flight trials programme mentioned in the previous section.

Table 5. Expected performance of fused positioning based on simulations

\begin{tabular}{|c|c|c|}
\hline & Mean Error $(\mathrm{m})$ & Standard Deviation of Error $(\mathrm{m})$ \\
\hline $\mathrm{E}$ & -0.9235 & 8.7375 \\
\hline $\mathrm{N}$ & -2.2386 & 35.6729 \\
\hline $\mathrm{U}$ & 0.4706 & 23.4983 \\
\hline
\end{tabular}

The DAA mitigation strategies for each trial have been defined in Table 6 . These provide safety assurance that the trials can be conducted, as well as providing a security mechanism to develop cUAS strategies by combining sensor capabilities to identify rogue and intruding aircraft. 
Table 6. DAA mitigation strategies

\begin{tabular}{|c|c|c|c|c|}
\hline Evidence & Trial 1 BVLOS in (closed) ATZ & Trial 2 BVLOS in (open) ATZ & $\begin{array}{l}\text { Trial } 3 \text { Segregated BVLOS in } \\
\text { NBEC (with TDA) }\end{array}$ & $\begin{array}{l}\text { Trial } 4 \text { Non-segregated BVLOS in } \\
\text { NBEC (no TDA) }\end{array}$ \\
\hline Mitigations & $\begin{array}{l}\text { ATZ active and staffed but } \\
\text { closed to all traffic except } \\
\text { NBEC UAS. }\end{array}$ & $\begin{array}{l}\text { ATZ active and staffed. ATZ } \\
\text { closed to non-cooperative traffic. } \\
\text { ATZ closed to visiting traffic. ATZ } \\
\text { open to pre-approved specific } \\
\text { Cranfield-based cooperative traffic. }\end{array}$ & $\begin{array}{l}\text { ATZ closed to all other traffic. } \\
\text { UAS only area defined for BVLOS } \\
\text { flight envelope. Issue NOTAM. } \\
\text { NBEC 'airspace' segregated by } \\
\text { means of TDA and monitored for } \\
\text { coop and non-cooperative aircraft. }\end{array}$ & $\begin{array}{l}\text { ATZ closed to all other traffic. UAS } \\
\text { only area defined for BVLOS flight } \\
\text { envelope. Issue NOTAM. NBEC } \\
\text { 'airspace' non-segregated and } \\
\text { monitored for coop and non-coop } \\
\text { aircraft. }\end{array}$ \\
\hline $\begin{array}{l}\text { Cooperative } \\
\text { (coop) Aircraft } \\
\text { (Manned) }\end{array}$ & $\begin{array}{l}\text { NOTAM issued, ATC open to } \\
\text { respond to radio calls from coop } \\
\text { aircraft and to monitor positions } \\
\text { of those that are ADS-B } \\
\text { equipped. Local Operators brief } \\
\text { in advance. }\end{array}$ & $\begin{array}{l}\text { Only Cranfield-based manned } \\
\text { aircraft operating. Mandate that } \\
\text { only those ADS-B equipped can } \\
\text { operate. ATC monitors segregation } \\
\text { through receipt of ADS-B info. } \\
\text { Local Operators briefed in advance. }\end{array}$ & $\begin{array}{l}\text { NOTAM issued for Sterile (pre- } \\
\text { defined, NOTAM'd) UAS-only } \\
\text { section of ATZ and NBEC } \\
\text { 'airspace'. ATC monitors } \\
\text { segregation through receipt of } \\
\text { ADS-B information. }\end{array}$ & $\begin{array}{l}\text { NOTAM issued for Sterile (pre- } \\
\text { defined, NOTAM'd) UAS only } \\
\text { section of ATZ and NBEC 'airspace'. } \\
\text { ATC monitors volume through } \\
\text { receipt of ADS-B information. }\end{array}$ \\
\hline $\begin{array}{l}\text { Cooperative } \\
\text { Aircraft } \\
\text { (Unmanned) }\end{array}$ & $\begin{array}{l}\text { All UAS ADS-B equipped (EC } \\
\text { approved spec) }\end{array}$ & $\begin{array}{l}\text { All UAS ADS-B equipped (EC } \\
\text { approved spec). UAS also fitted } \\
\text { with Vodafone RPS for evaluation. }\end{array}$ & \multicolumn{2}{|c|}{$\begin{array}{l}\text { All UAS ADS-B equipped (EC approved spec). UAS fitted with RPS as } \\
\text { backup system (expect to have reduced accuracy vs ADS-B). }\end{array}$} \\
\hline $\begin{array}{l}\text { Non- } \\
\text { cooperative/ } \\
\text { non- } \\
\text { communicative } \\
\text { (NC2) Aircraft }\end{array}$ & $\begin{array}{l}\text { NOTAM issued. Non-compliant } \\
\text { Local Operators briefed in } \\
\text { advance. }\end{array}$ & $\begin{array}{l}\text { ATZ closed to NC2 aircraft. } \\
\text { Accuracy of Holographic Radars } \\
\text { feeds to be identified in advance } \\
\text { using LOS/EVLOS flight. Non- } \\
\text { compliant Local Operators briefed } \\
\text { in advance. }\end{array}$ & $\begin{array}{l}\text { RP monitors NC2 aircraft position } \\
\text { and velocity detected using } \\
\text { Holographic Radar, to a known } \\
\text { accuracy. }\end{array}$ & $\begin{array}{l}\text { RP monitors NC2 aircraft position } \\
\text { and velocity detected using } \\
\text { Holographic Radar, to a known } \\
\text { accuracy. }\end{array}$ \\
\hline \multirow[t]{2}{*}{$\begin{array}{l}\text { Tactical } \\
\text { Collision } \\
\text { Avoidance }\end{array}$} & \multicolumn{2}{|c|}{$\begin{array}{l}\text { RP has visibility of UAS location from GCS (GPS derived). ATC has } \\
\text { visibility of UAS location from ADS-B received (GPS derived). }\end{array}$} & \multicolumn{2}{|c|}{$\begin{array}{l}\text { RP has visibility of UAS location from GCS (GPS derived), and other } \\
\text { traffic from Holographic radar feed. ATC has visibility of UAS location } \\
\text { from ADS-B received (GPS derived). UAS restricted to specific area } \\
\text { through use of Geofencing. ATC has visibility of all aircraft together with } \\
\text { their position and velocity within ATZ and NBEC, to known accuracies. }\end{array}$} \\
\hline & & $\begin{array}{l}\text { UAS restricted to Sterile (pre- } \\
\text { defined, NOTAM's) area through } \\
\text { use of Geofencing. }\end{array}$ & & \\
\hline
\end{tabular}




\section{Conclusions}

This paper describes the current progress in development of the drone experimentation facility and enabling ecosystem - NBEC, identifying some of the main challenges that it will address. The ecosystem intends to establish the building blocks underpinned by a trials strategy with incremental evidence gathering to demonstrate safe integration of manned and unmanned aircraft, enable routine BVLOS operations in non-segregated airspace and subsequently allow it to become a trials facility available for other users. The NBEC is a modular and 'plug and play' ecosystem, where new concepts, systems and solutions can easily be integrated and tested (at scale if necessary) in a real operational environment. The ecosystem provides along with the DAA also cUAS capabilities that combine radar and supplementary sensor functionalities to detect and identify rogue and intruding air vehicles.

A synthetic environment that accurately represents the real-life sensor architecture (radar and RPS at this stage) and includes a fusion capability provides preliminary results that supports the performance validation activity, ahead of the real flight trials.

The consortium works closely with the UK CAA's Innovation Hub, to ensure that the solutions and services developed to address these challenges are future proofed and aligned with extant and emerging regulations. Close collaboration with NSAs is fundamental, as well as ensuring lessons learnt, results and best practices are discussed and shared with the industry.

\section{References}

[1] CAA CAP670 Air Traffic Services Safety Requirements June 2019.

[2] EUROCONTROL Specification for ATM Surveillance System Performance (Volumes 1 \& 2), Ed. 1.1. September 2015.

[3] M. Jahangir and C. J. Baker, "Persistence Surveillance of Difficult to Detect micro-drones with L-band Holographic Radar", CIE 2016 IRS, Guangzhou, China, October 2016.

[4] M. Jahangir and C. J. Baker, "Characterisation of low observable targets with a multi-beam staring radar", IET Radar 2017, Belfast, UK, October 2017.

[5] M. Jahangir and C. J. Baker, "L-band staring radar performance against micro-drones", International Radar Symposium (IRS) 2018, Bonn, Germany, June 2018.

[6] Vodafone, "Beyond Visual Line of Sight Drone Trial Report", November 2018.

[7] Vodafone, "Network-Based Drone Airspace Management Trial Report", December 2019.

[8] CAA Innovation Hub CAP1861 A, "Detect \& Avoid Ecosystem for BVLOS in Non-Segregated Airspace", October 2020.

[9] G. Lykou, D. Moustakas, D. Gritzalis, "Defending Airports from UAS: A Survey on CyberAttacks and Counter-Drone Sensing Technologies" Sensors 20, 2020.

[10] A. H. Michel, 'Counter-drone systems", Center Study Drone Bard College, Bard College, NY, USA, December 2019.

[11] K. Honggu, J. Jingon, K. Jinyoung, K. Joonhyuk, S. C. Tong, "Protect your sky: A survey of counter unmanned aerial vehicle systems." IEEE Access 8 (2020). 


\section{Developing drone experimentation}

\section{facility: progress, challenges and cUAS considerat}

Panagiotakopoulos, Dimitrios

IEEE

Panagiotakopoulos D, Williamson A, Petrunin I, et al., (2021) Developing drone experimentation facility: progress, challenges and cUAS consideration. In: 202121 st International Radar

Symposium (IRS), 21-22 June 2021, Berlin

https://doi.org/10.23919/IRS51887.2021.9466204

Downloaded from Cranfield Library Services E-Repository 